\title{
Machine Learning Based Improved Automatic Diagnosis of Cardiac Disorder
}

\author{
Neelesh Srivastava \\ Jetking Infotrain Limited, Aliganj \\ Center, Lucknow, Uttar Pradesh, \\ India \\ neelesh.bluesky@gmail.com
}

\author{
Mansi Bhatnagar \\ Center for Advanced Studies, Dr. \\ A.P.J. Abdul Kalam Technical \\ University, Lucknow, Uttar Pradesh \\ India \\ mansi.v113@gmail.com
}

\author{
Anjali Yadav \\ Center for Advanced Studies, Dr. \\ A.P.J. Abdul Kalam Technical \\ University, Lucknow, Uttar Pradesh, \\ India \\ anjaliyadav1109@gmail.com
}

\author{
Malay Kishore Dutta \\ Center for Advanced Studies, Dr. A.P.J. Abdul Kalam \\ Technical University, Lucknow, Uttar Pradesh, India \\ malaykishoredutta@gmail.com
}

\author{
Carlos M Travieso \\ Signals and Communication Department, IDeTIC, \\ University of Las Palmas de Gran Canaria, Las \\ Palmas de Gran Canaria, Spain \\ carlos.travieso@ulpgc.es
}

\begin{abstract}
Heart diseases are one of the most common diseases these days. The common cardiovascular diseases are usually being diagnosed by the manual stethoscope by doctor. In many developing countries doctors are not available in primary health care centers in rural areas. This paper proposes a method to diagnose and detect the abnormal heart frequencies using discriminatory features of the heart sound by machine learning. Mel frequency cepstral coefficients study has been done to excerpt the features from the heart sound, which increases the sensitivity of the results. Support Vector Machine is used to train and test the features extracted. The proposed method uses the Butterworth filter for pre-processing of noise removal to clean the signal. Time complexity has been decreased and due to the logic implemented the device database can get update by itself as far as it gets in use and doesn't need human intervention making it completely automatic. The proposed method is tested on a comprehensive database of heart sounds with different non-overlapping testing sets. The proposed method achieved the best accuracy of $95 \%$ during classification process. The experiment results indicate that the proposed method is efficient for classification of healthy/unhealthy heart sounds and computationally cheap making it suitable for real time applications.
\end{abstract}

\section{CCS CONCEPTS}

- Applied Computing $\rightarrow$ Computer in other domains - Information Systems $\rightarrow$ Information Retrieval • Computer Systems Organization $\rightarrow$ Dependable and fault- tolerant systems • Human-centered Computing $\rightarrow$ Human Computer Interaction

\footnotetext{
Permission to make digital or hard copies of all or part of this work for personal or classroom use is granted without fee provided that copies are not made or distributed for profit or commercial advantage and that copies bear this notice and the full citation on the first page. Copyrights for components of this work owned by others than ACM must be honored. Abstracting with credit is permitted. To copy otherwise, or republish, to post on servers or to redistribute to lists, requires prior specific permission and/or a fee. Request permissions from Permissions@acm.org. APPIS 2019, January 7-9, 2019, Las Palmas de Gran Canaria, Spain (C) 2019 Association for Computing Machinery. ACM ISBN 978-1-4503-6085-2/19/01 ..\$15.00 DOI: https://doi.org/10.1145/3309772.3309783
}

\section{KEYWORDS}

Cardiovascular; Cepstrum; Machine Learning; Butterworth filter; MFCCs; Support Vector Machine

\section{INTRODUCTION}

As per the Report by WHO 17.9 Million people die every year from cardiovascular diseases, and greater than $75 \%$ deaths occurred in low income and middle-income countries. Cardiac disorder is identified by an abnormal sound due to the propagation of the regular heart sound along with the sound of the murmurs No doubt there are a huge number of cardiologists being present in diagnostic centers, but still there are major number of diagnostic center where they lack the doctors. So, there must be a way to fulfill the need of the heart patients by some diagnostic tool. The preferred diagnostic tool can diagnose whether there is any cardiac disorder or not. Nadia Masood

Khan et al [1] proposed different algorithms which have been implemented for automated heart sound classification using PCG, SVM, ANN, and CGPANN (Cartesian Generic Programming evolved Artificial Neural Network). S. Hussain et al. [2] researched on the methodology of classification of heart sound based on multipoint auscultation system. Altman, DG [3] proposed method to diagnose the $\mathrm{PCH}$ on the basis of Sensitivity and Specificity. Machineti Vadicherla et al [4] proposed a decision support system for heart disease based on sequential minimal optimization in support vector machine. D. Kumar et al [5] proposed Heart murmur classification with feature selection. The above contribution of the researchers has motivated and encouraged to work in the area of applications of computer science in medical field. The computer based automatic diagnoses of the heart sound to test the abnormality of the heart can be an efficient method of early stage screening of the cardio vascular diseases in primary health care centers.

Although these existing works and their experimental results reported are interesting and encouraging, but still there is a requirement to design a more accurate and efficient system for automated diagnosis of heart diseases from heart sounds which can work in real time. Machine learning based diagnosis of cardiac disorder maybe helpful in early diagnosis of cardiac diseases, as it improvises the filtering technique by use of Butterworth filter and can update the database by itself without any human intervention. 
The main contribution of the proposed method is that it follows the iteration method using discriminatory Mel frequency cepstral coefficients statistical mean and median as perceptual features and SVM's Linear kernel classifier, in which the training data will improve itself by updating the set of values where the training data is being saved making the system completely automatic and will suit real time applications.

In addition, the proposed method has the advantage that since the values are not stored in an array with in the program, it will decrease the SLOC value which further it will decrease the space complexity for the same cause and will eliminate the requirement of periodic updating.

The remaining paper consists of the following sections: Section 2 consist of a signal processing technique along with the methodology for machine learning schema. Section introduces the conclusion of the results obtained from experimenting the various heart sounds for classification, training and testing.

\subsection{Database Used: Heart Sounds}

In the proposed work, Experiments were carried on the Heart sounds database created under Physionet Challenge 2016 [8]. The recorded sounds are either from healthy subjects or pathological patient. Each audio belongs from one patient only and the existence of same patient file is most unlikely in the sets. This database contains total of 3923 heart sounds recording which are divided into five sets of databases (A to E) and sets contains both normal as well as abnormal sounds for training and testing purpose. The heart sounds were recorded from different body locations including four main locations Aortic area, mitral area, tricuspid area and pulmonic area. These four locations are mostly used by doctors to listen heart sounds. The database is divided into two parts: abnormal heart sound and normal heart sound. The abnormal heart sounds were recorded from patient with confirmed cardiac disease typically heart valve defects and coronary artery diseases while the normal heart sounds were recorded form the healthy subjects. Recorded heart sounds of this database belong to both children as well as adults. All heart sounds are re-sampled to $2,000 \mathrm{~Hz}$ and available in .wav format. Each heart sound contains one phonocardiogram (PCG) lead i.e. a graphical representation of a heart sound recording.

\section{THE PROPOSED FRAMEWORK}

The main purpose of this work is to design a machine learning based system for automatic diagnosis of cardiac diseases using heart sounds. The proposed method is explained in Fig. 2 by the flow diagram. The proposed framework involves strategic processing and resampling of heart sounds to extract edifying features followed by analysis to find out most prominent features for classification. The preprocessing of the signal includes the resampling of the sound followed by the Butterworth filter to remove the noise. Many extracted features were analyzed and on the basis of study the MFCC statistical mean and Median values, were most discriminative features and were subjected to classifiers for automatic classification of normal/abnormal heart sounds. To test the performance of proposed machine learning based system for classification of heart sounds machine learning based algorithms were used. The proposed model is categorized into five sub-sections: resampling of the heart sound, Butterworth filtering, feature extraction, and supervised classification of normal/abnormal heart sounds. The further process Fig. 2 shows the flow chart diagram of the proposed framework for machine learning based diagnosis of cardiac disorder.

Heart frequencies are also different for the normal and abnormal hearts both. Experienced physicals and cardiologists can take the benefits of the machine learning which is not so far entered in the mentioned track.

Figure 2 depicts the block diagram for the methodology used to classify the heart sound as normal or abnormal. The abnormal sound states the condition of cardiac disorder. The diagram explains that the recorded PCG heart sound is then processed and been pass through Butter worth filter. The obtained result is then used for feature extraction.

\subsection{Features of the Heart Sound Signal}

The heart sound signals can be classified into five broad features which are:

i. Time Domain Features, which contains RMS, Energy, and Zero Crossing Rates;

ii. Spectral features, which contains Amplitude Spectrum, Power Spectrum, Spectral Centroid, Spectral Flux, Spectral Slope, Spectral Roll off, Spectral Spread, Spectral skewness, Spectral Kurtosis, and Chroma;

iii. Perceptual Features, which contains Loudness, Perceptual Spread, Perceptual Sharpness, and MFCC;

iv. Utility Extractors, which contains Complex Spectrum, and Buffer;

v. Windowing Functions, which contains Hanning, Sine, Hamming, Rectangular, and Blackman

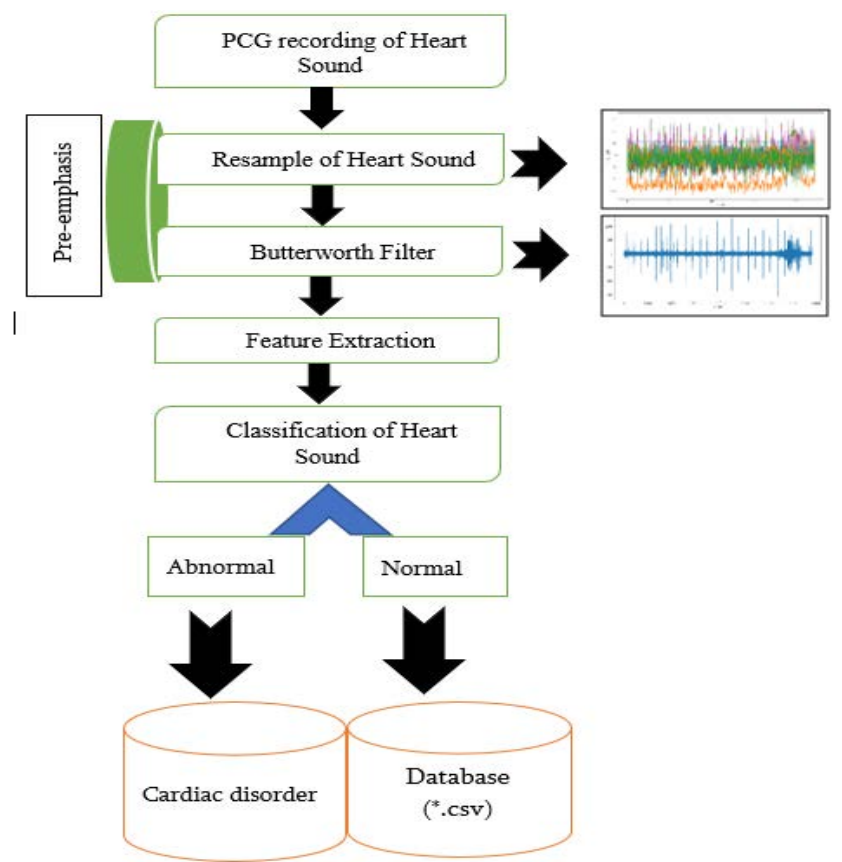

Fig 1: Block Diagram of the methodology used to classify the heart sound and automatic updating of the database

\subsection{Recording and Pre-processing of PCG Wave}

Phonocardiogram frequency or PCG frequency has been sampled and recorded the signal is being pre-processed at the rate of 44100 by 1 channel and has been recorded for 15 seconds the different frames of the wave than get joined into a signal audio frequency. The obtained frequency is than entered into the low pass butter worth filter and the corresponding MFCC mean and MFCC median has been obtained and being used with the training data set with the help of support vector machine supervised classifier.

\subsection{Features studied.}

Possible discriminatory features for automatic classification of heart sound are Spectral centroid, Energy entropy, Spectral rolloff, Spectral flux and MFCC as discussed in this section. 


\subsubsection{Spectral centroid}

Heart sound is the vibrations produced because of periodic opening and closure of heart valves. In case of cardiac diseases which mainly causes heart valve defect, the heart valve fails to open and close normally that may likely cause changes in frequencies of the heart vibration. Spectral centroid gives the information about dominant frequency of an audio signal changes over time which may have discrimination between heart sound of healthy subjects and heart valve defect patients.
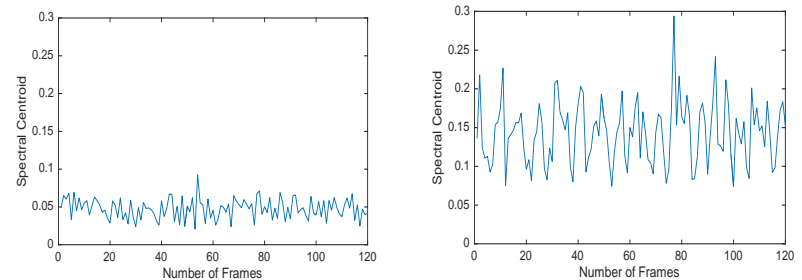

Fig. 2: Spectral Centroid: (a) Normal heart sound (b) Abnormal heart Sound

\subsubsection{Energy Entropy}

The beating of heart and flow of blood thorough it generates heart sound. In the coronary heart disease, coronary arteries become narrow resulting restriction of blood flow to heart and irregular heartbeat. Because of irregular heartbeat of cardiac patients, there is a possibility of change in energy levels of heart sounds for healthy subjects and cardiac patients. Energy entropy of audio signal indicates the abrupt changes observed in energy levels of an audio signal which may differentiate abnormal/normal heart sounds.
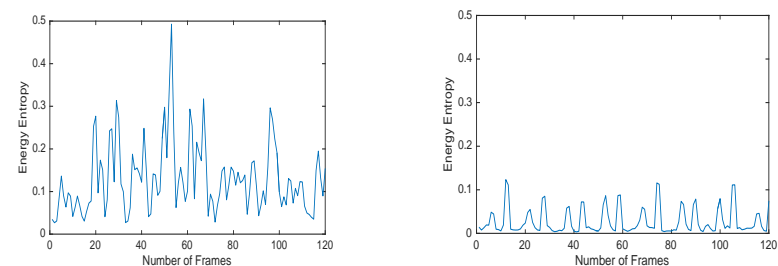

Fig. 3. Energy Entropy (a) Normal heart sound (b) Abnormal heart Sound

\subsubsection{Spectral Rolloff:}

Heart vibrations correspond to the mechanical activity of the cardio hemic system. Heart valve does not work properly in cardiac patients which causes change in the frequency distribution of heart vibrations. There may be a possibility of change in power spectral distribution of heart sounds recoded from healthy subjects and patients of cardiac diseases.
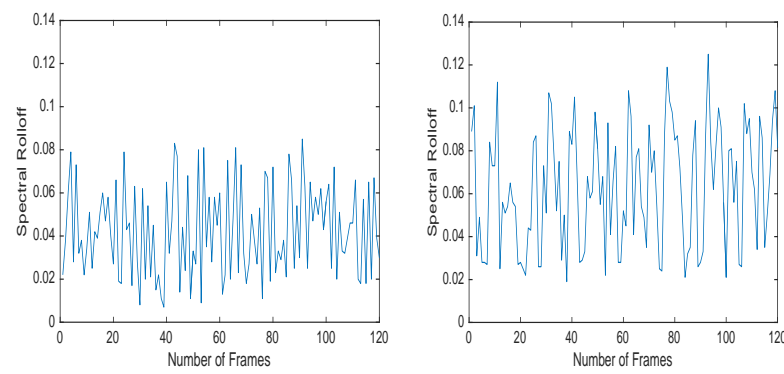

Fig. 4. Spectral Rolloff (a) Normal heart sound (b) Abnormal heart Sound

Spectral Rolloff of audio signals a measure of spectral power distribution which maybe a discriminative parameter for separation of normal/abnormal heart sounds.

\subsubsection{Spectral Flux:}

Opening and closing of heart valve which is directly responsible for heart sound is not proper for the patients of cardiac diseases. In the case of heart sound recorded from cardiac patient, there could be some other abnormal sounds in the PCG signal (phonocardiogram: graphical representation of a heart sound recording) besides primary heart sounds. These abnormal sounds are generally high-frequency sound and it normally refers to different pathological conditions. It may be differentiating from normal heart sounds by spectral flux of signal which is a measure to check the rate of change of power spectrum of a signal. It can be determined by comparing one frame of power spectrum with the previous frame.

\subsubsection{Mel Frequency Cepstral Coefficients}

Mel Frequency Cepstrum Coefficients are the values that represent audio based on perception and are derived from the Mel frequency cepstrum. This method is considered to be the best available approximation of human ear because it provides the highest sensitivity value as in compared with other factors.
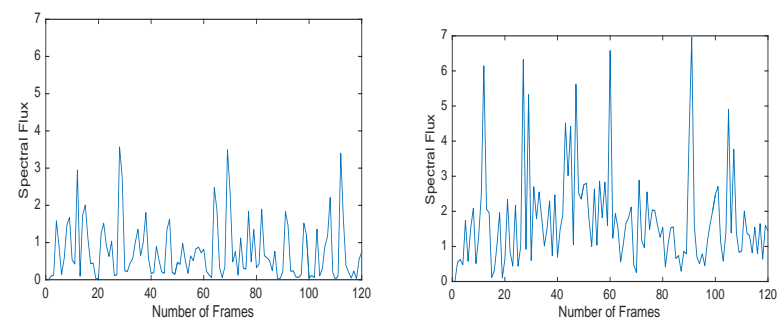

Fig. 5: Spectral Flux (a) Normal heart sound (b) Abnormal heart Sound

As soon as the normal heart sound recorded the murmurs of the heart which acts as the noise for that particular normal sound wave enters into the same, changes the property of the wave frequency which gives us the advantage of automatic classification of the abnormal sound from the normal sound. The process methodology for machine learning includes the PCG recordings of the heart sounds along with the feature extraction which is MFCC in this proposed paper.

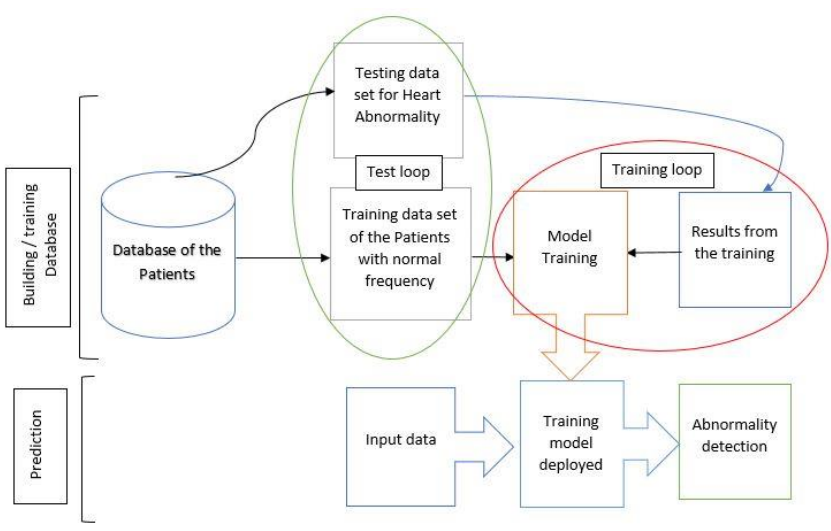

Fig. 6: Machine learning Methodology

Fig. 6 depicts the methodology of machine learning and collection of the tested data in the training data if satisfies the standard equation.it shows that if training data are $(\mathrm{X} 1, \mathrm{X} 2, \ldots \ldots \ldots \ldots . \mathrm{Xy} . .$. $\mathrm{Xn}$ ) having weight as (W1,W2, ...Wy ... Wn).

If Xp satisfies the equation then it will be appended to the training data set. It explains that the PCG recorded signals are being preprocessed and being set for training data set which act as the standard for the future tests. If the testing frequency matches the 
standard of the training data it is declared as normal and is appended to training data set in return of which, it increases the data base which is an essential feature of learning (i.e., vast data base). along with that the classifier and function are also being saved as the weight to the given input frequencies which further increases the artificial intelligent of the machine and the proposed methodology. Further for the next testing frequency the previous appended frequencies will act as the training data set.

\subsection{Feature Extraction}

Mel-Frequency Cepstral Coefficient is being used as the discriminatory feature for the frequencies MFCCs is derived as follows:

1. Take the fast Fourier transform of a PPG signal.

2. The powers of the FFT spectrum obtained above onto the Mel scale been mapped, using window of triangular overlapping.

3. Calculate the Mel log powers by taking the logs of the powers at each of the Mel frequencies.

4. Take the discrete cosine transform of the list of Mel log powers, as if it were a signal.

5. The MFCCs are the amplitudes of the resulting spectrum

Logarithmic equation of MFCC's Mel scale:

$$
m=2595 \log _{10}\left(1+\frac{f}{700}\right)
$$

The Pre-emphasis is grounded on contributive relation in the timedomain as stated below:

$$
y[n]=s[n]-a * s[n-1], 0.9 \leq a \leq 1.0
$$

; $y[n]=$ filter for outcome of signal pre-emphasizes and $s[n]=$ earlier signal pre-emphasize filter.

The Fast Fourier transformation is to decompose the signal into a sinusoidal signal, which consists of two units namely real and imaginary unit. FFT is an algorithm that implements Discrete Fourier Transformation (DFT), which is the conversion of each frame with $\mathrm{N}$ sample in time - frequency domain.

$$
X_{n}=\sum_{k=0}^{N-1} X_{k} e^{-\frac{2 \pi j k n}{N}}
$$

Where: $\mathrm{N}=$ The number of framing sections and $\mathrm{X}=$ Data value for $\mathrm{k}$. The logarithmic values are obtained by converting DFT values into a single value. The obtained function is known as Mel value:

$$
m=2595 \log _{10}\left(1+\frac{f}{700}\right)
$$

Figure 7 shows the process of extracting the feature of MFCC from the PCG as the distinguishable feature to diagnose the cardiac disorder.

The classification is used to categorize the various features of the particular object or physical quantity. The classifier is the standard measure for any physical quantity to decide the category to which it belongs and to make it distinguishable from the other instances of the same class. There are various features of the PCG which can be classified that are discussed in above section, but the MFCC is used cause being its distinguishability, and the classifier deployed for such purpose is Support Vector Machine (SVM). One of the classifiers which is discriminately and formally defined by a separating hyperplane is Support Vector Machine (SVM). In two-dimensional (2D) spatial the discussed hyperplane is a separating line between two classes which are being classified for the purpose of discrimination. "Support Vector Machine" (SVM) is a supervised machine learning procedure which can be used for either cataloging or reversion encounters.

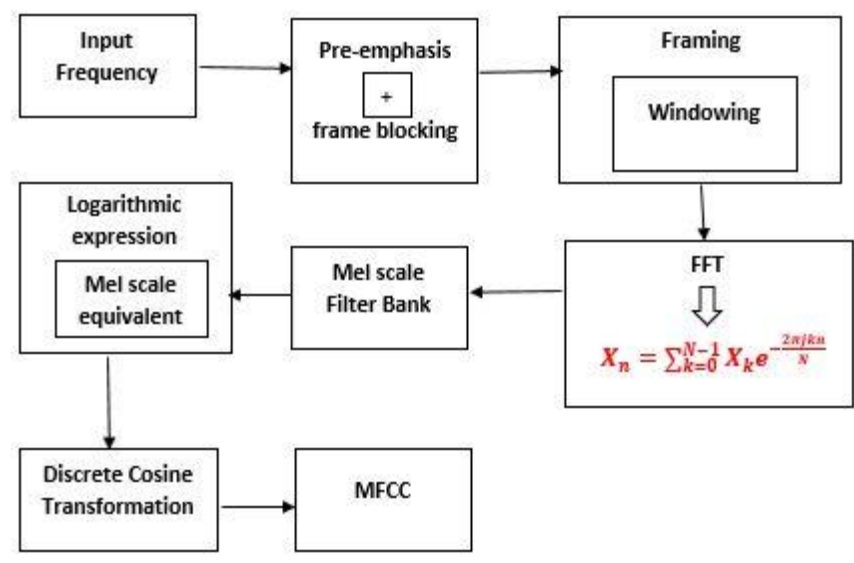

Fig. 7. Block diagram of the MFCC

\section{EXPERIMENTAL OBSERVATIONS}

The proposed work uses, the 2016 PhysioNet/CinC Challenge database [10] for validation purpose. The device/equipment used to record the abnormal and normal sounds of the heart sounds / frequencies is phonocardiogram.

The cardiac disorder is the cause for the abnormal heart sounds that further results into the noisy signal as recorded by the Phonocardiogram (PCG). The resampled wave is being processed by the Butterworth filter. Below given are the plots obtained for both normal and abnormal for before and after the filtering.

The catalogue containing of an overall 100 heartbeat signals has been used. The whole database is divided into two sets, the first set is named as $\mathrm{X}$ which contains the normal sounds while the second set is named as $\mathrm{Y}$ which contains the abnormal sounds of the heart recorded using phonocardiogram. Out of 50 samples from both the classes, 35 has taken training and 15 has been used for testing purpose and cross validation has been done in an iterative manner.

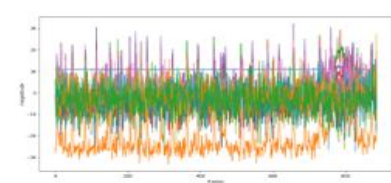

(a)

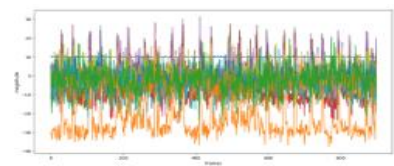

(a)

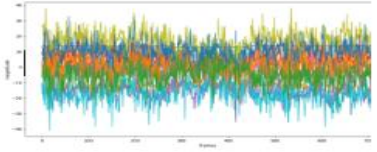

(a)

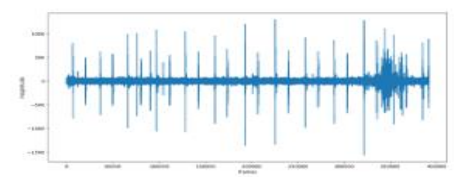

(b)

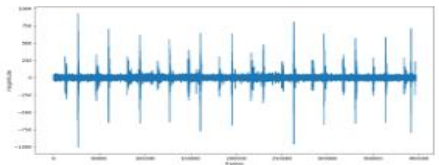

(b)

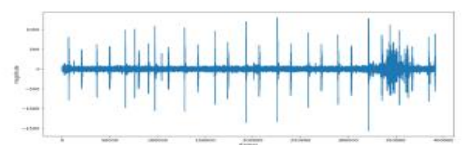

(b)
Fig. 8: (a) Normal PCG before filtering (b) Normal PCG after filtering, with number of frames at $\mathrm{X}$-axis and Magnitude at y-axis. 


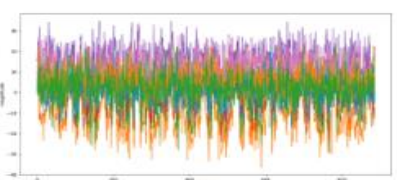

(a)

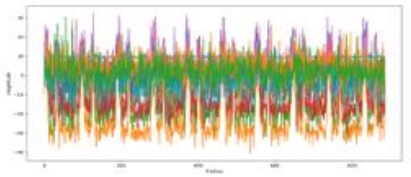

(a)

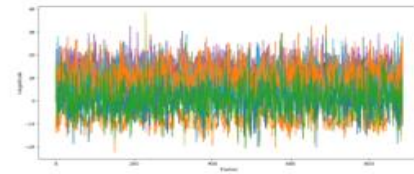

(a)

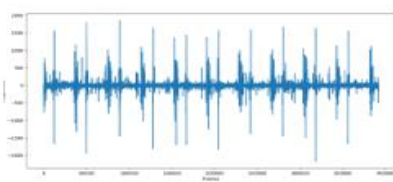

(b)

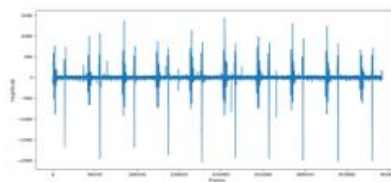

(b)

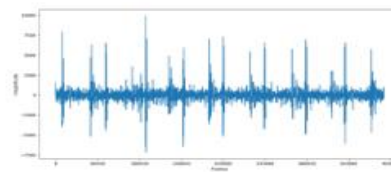

(b)
Fig. 9: (a) Abnormal PCG before filtering (b) Abnormal PCG after filtering, with number of frames at $\mathrm{X}$-Axis and magnitude at $\mathbf{Y}$-axis

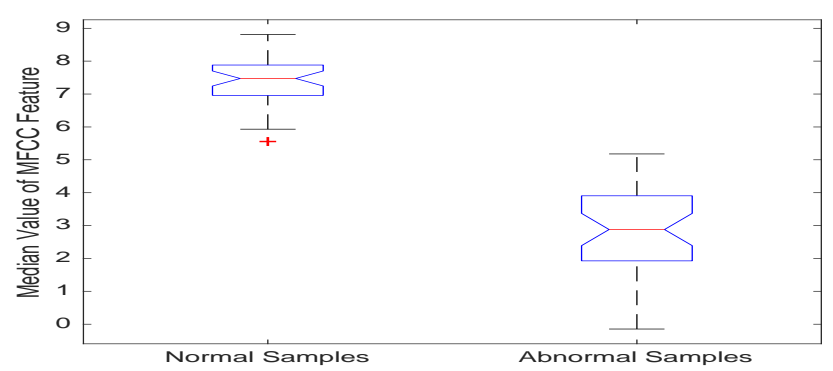

(a)

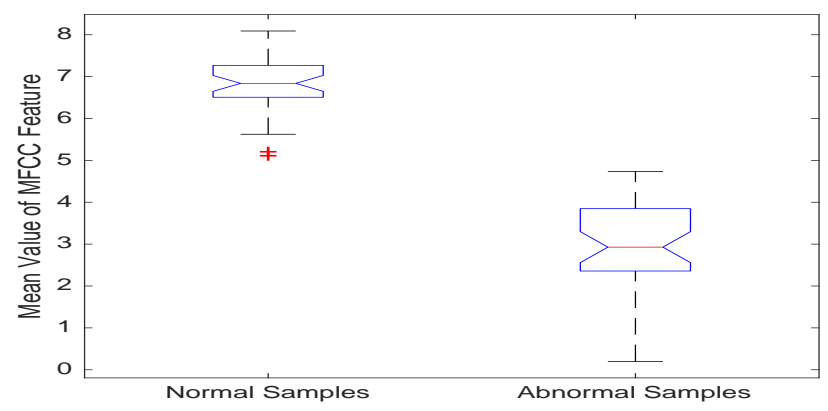

(b)

Fig. 10: (a) Box plots of mean value of MFCC feature extracted from normal and abnormal samples (b) Box plots of median value of MFCC feature extracted from normal and abnormal samples

Fig. 11 depicts the application plot of SVM's Linear kernel to predict the relationship between the mean and median of the training and testing samples. The SVM classifier shows better sensitivity and has the large probability to gain the accuracy by linear kernel.

Table 2. contains 15 Normal PCG's corresponding values of MFCC Mean and MFCC Median and the Accuracy. The term Accuracy is meant to the preciseness of the proposed method to validate the testing data to its training behaviors. The Value "1" shows that the PCG sound that has been chosen is categorized as
Normal and value " 0 " states that the PCG sound is Abnormal or there is Cardiac Disorder.

Table III explains the classification and performance results of the PCG sounds as chosen in Table I. True Positives are total number of

abnormal samples classified as abnormal. True Negatives s the total number of samples classified as Normal. False Negatives is the total number of abnormal samples classified as normal. False Positives is the total number of normal samples classified as abnormal Negatives and False Positives. Table IV presents a comparative table for comparing the proposed method with some other methods.

Under Performance result, Accuracy is the percentage of True Results over all the taken samples. Sensitivity is the percentage of having the True positives over True Positives and False negatives. Specificity is the percentage of having True Negatives over the True Positives.

Fig. 11: Mean and Median values of Training and testing samples using Linear Kernel

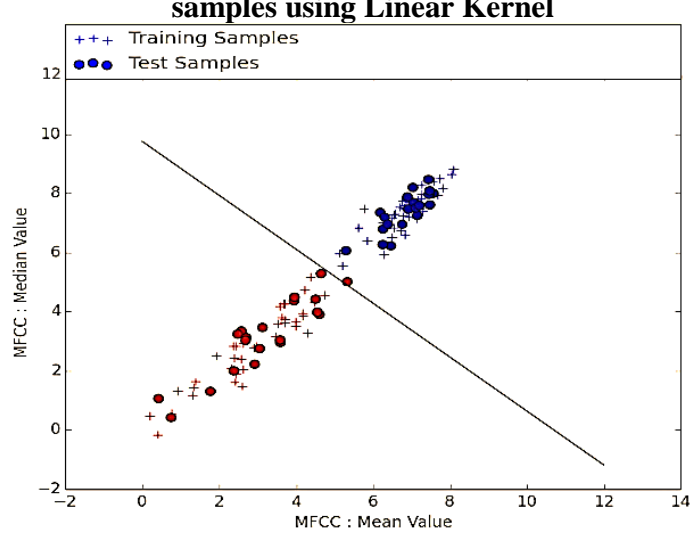

Table 2. Accuracy in The Feature Extraction Values for Normal and Abnormal Samples of Heart Sound

\begin{tabular}{|c|c|c|c|c|}
\hline \multicolumn{5}{|c|}{ Accuracy in the Features Extraction } \\
\hline S1. No & \multicolumn{2}{|c|}{ MFCC Mean } & \multirow{2}{*}{$\begin{array}{c}\text { MFCC } \\
\text { Median } \\
-1.62993\end{array}$} & \multirow{2}{*}{$\begin{array}{c}\text { Accuracy } \\
1\end{array}$} \\
\hline \multirow{13}{*}{$\begin{array}{c}\text { Normal } \\
\text { Sound }\end{array}$} & 1 & -1.7588 & & \\
\hline & 2 & 7.151043 & 7.854533 & 1 \\
\hline & 3 & -0.15529 & 0.301817 & 0 \\
\hline & 4 & 0.714829 & -0.3333 & 1 \\
\hline & 5 & -2.71514 & -2.33362 & 1 \\
\hline & 6 & 1.302054 & 0.600316 & 1 \\
\hline & 7 & -6.21541 & -689528 & 1 \\
\hline & 8 & -0.79349 & -0.54916 & 1 \\
\hline & 9 & 3.444598 & 4.714747 & 1 \\
\hline & 10 & -2.88028 & -3.1823 & 1 \\
\hline & 11 & -2.64807 & -2.81321 & 1 \\
\hline & 12 & 1.305089 & 1.656543 & 1 \\
\hline & 13 & 0.921943 & 1.593867 & 1 \\
\hline
\end{tabular}




\begin{tabular}{|c|c|c|c|c|}
\hline & 14 & -1.4389 & -1.15079 & 0 \\
\hline & 15 & -1.88053 & -1.4739 & 1 \\
\hline \multirow{15}{*}{$\begin{array}{l}\text { Abnormal } \\
\text { Sound }\end{array}$} & 1 & 1.415001 & 1.025004 & 0 \\
\hline & 2 & 1.855651 & 1.452267 & 0 \\
\hline & 3 & 2.208191 & 2.130687 & 0 \\
\hline & 4 & -1.00419 & -1.73085 & 0 \\
\hline & 5 & -1.31322 & -2.27133 & 0 \\
\hline & 6 & -0.01475 & -0.06035 & 0 \\
\hline & 7 & -0.08346 & -0.47535 & 0 \\
\hline & 8 & 0.434098 & -0.10376 & 0 \\
\hline & 9 & -1.7384 & -2.11764 & 0 \\
\hline & 10 & $0.13 \operatorname{cccc} 1$ & -0.15599 & 0 \\
\hline & 11 & -1.30507 & -1.3875 & 0 \\
\hline & 12 & -0.1201 & -0.47066 & 0 \\
\hline & 13 & -1.69084 & -0.95547 & 0 \\
\hline & 14 & -1.35933 & -1.09523 & 0 \\
\hline & 15 & -1.55657 & -1.13194 & 0 \\
\hline
\end{tabular}

Table 3. Confusion Matrix for different non-overlapping set of training and testing dataset

\begin{tabular}{|c|c|c|c|c|c|}
\hline \multirow{3}{*}{\multicolumn{2}{|c|}{$\begin{array}{l}\text { CONFUSION } \\
\text { MATRIX }\end{array}$}} & & & & \\
\hline & & \multirow{2}{*}{$\begin{array}{c}\text { TRAINING } \\
\text { CONDITIO } \\
\mathrm{N}\end{array}$} & \multirow{2}{*}{$\begin{array}{c}\text { TESTING } \\
\text { CONDITI } \\
\text { ON }\end{array}$} & \multicolumn{2}{|c|}{$\begin{array}{l}\text { PREDICTED } \\
\text { CONDITION }\end{array}$} \\
\hline & & & & $\begin{array}{c}\text { Norm } \\
\text { al }\end{array}$ & $\begin{array}{c}\text { Abnor } \\
\text { mal }\end{array}$ \\
\hline \multicolumn{6}{|c|}{ Case-I } \\
\hline \multirow{2}{*}{$\begin{array}{c}\text { True } \\
\text { Conditio } \\
n\end{array}$} & $\begin{array}{c}\text { Norma } \\
1 \text { Heart } \\
\text { Sound }\end{array}$ & 30 & 20 & 19 & 1 \\
\hline & $\begin{array}{c}\text { Abnor } \\
\text { mal } \\
\text { Heart } \\
\text { Sound } \\
\end{array}$ & 30 & 20 & 1 & 19 \\
\hline \multicolumn{6}{|c|}{ Case-II } \\
\hline \multirow{2}{*}{$\begin{array}{l}\text { True } \\
\text { Conditi } \\
\text { on }\end{array}$} & $\begin{array}{c}\text { Norma } \\
1 \text { Heart } \\
\text { Sound }\end{array}$ & 35 & 15 & 15 & 0 \\
\hline & $\begin{array}{c}\text { Abnor } \\
\text { mal } \\
\text { Heart } \\
\text { Sound } \\
\end{array}$ & 35 & 15 & 2 & 13 \\
\hline \multicolumn{6}{|c|}{ Case-III } \\
\hline \multirow{2}{*}{$\begin{array}{l}\text { True } \\
\text { Conditi } \\
\text { on }\end{array}$} & $\begin{array}{l}\text { Norma } \\
1 \text { Heart } \\
\text { Sound } \\
\end{array}$ & 40 & 10 & 10 & 0 \\
\hline & $\begin{array}{c}\text { Abnor } \\
\text { mal } \\
\text { Heart } \\
\text { Sound } \\
\end{array}$ & 40 & 10 & 1 & 9 \\
\hline
\end{tabular}

Table 5. Comparative Study Chart

\begin{tabular}{|c|c|c|c|c|c|c|c|}
\hline Reference & Objective & Database Used & $\begin{array}{l}\text { Features } \\
\text { Considered }\end{array}$ & $\begin{array}{c}\text { Criteria } \\
\text { for } \\
\text { Feature } \\
\text { Selection }\end{array}$ & $\begin{array}{l}\text { Classification } \\
\text { Method }\end{array}$ & Accuracy & $\begin{array}{c}\text { CPU } \\
\text { Time(in } \\
\text { seconds) }\end{array}$ \\
\hline $\begin{array}{c}\text { N.Masood } \\
\text { Khan et al } \\
{[1]}\end{array}$ & $\begin{array}{c}\text { Automated Heart } \\
\text { Sound } \\
\text { Classification } \\
\text { from } \\
\text { Unsegmented } \\
\text { Phonocardiogram } \\
\text { Signals Using } \\
\text { Time Frequency } \\
\text { Features } \\
\end{array}$ & $\begin{array}{l}\text { PhysioNet/CinC } \\
\text { challenge } 2016\end{array}$ & $\begin{array}{l}10 \text { features } \\
\text { extracted }\end{array}$ & $\begin{array}{c}\text { Not } \\
\text { Reported }\end{array}$ & $\begin{array}{c}\text { SVM, } \\
\text { CGPANN }\end{array}$ & $73.64 \%$ & $\begin{array}{c}\text { Not } \\
\text { Reported }\end{array}$ \\
\hline $\begin{array}{l}\text { Machineti } \\
\text { Vadicherla } \\
\text { et al. [4] }\end{array}$ & $\begin{array}{l}\text { Decision support } \\
\text { system for heart } \\
\text { disease based on } \\
\text { sequential } \\
\text { minimal } \\
\text { optimization in } \\
\text { support vector } \\
\text { machine }\end{array}$ & $\begin{array}{l}\text { UCI machine } \\
\text { learning } \\
\text { repository data } \\
\text { of Cleveland } \\
\text { heart disease } \\
\text { database }\end{array}$ & $\begin{array}{l}\text { Lagrange } \\
\text { multiplier }\end{array}$ & $\begin{array}{l}\text { Not } \\
\text { reported }\end{array}$ & SMO, SVM & $\begin{array}{c}\text { Not } \\
\text { Reported }\end{array}$ & $\begin{array}{c}\text { Not } \\
\text { Reported }\end{array}$ \\
\hline $\begin{array}{l}\text { G. } \\
\text { Redlarski } \\
\text { et. al. [9] }\end{array}$ & $\begin{array}{l}\text { A System for } \\
\text { Heart Sounds } \\
\text { Classification }\end{array}$ & $\begin{array}{l}\text { Local data base } \\
160 \text { recording }\end{array}$ & Waveform & $\begin{array}{c}\text { Not } \\
\text { Reported }\end{array}$ & LPC, SVM & $92.36 \%$ & $\begin{array}{c}\text { Not } \\
\text { Reported }\end{array}$ \\
\hline $\begin{array}{l}\text { Yuenyong } \\
\text { S et al } \\
{[12]}\end{array}$ & $\begin{array}{c}\text { A framework for } \\
\text { automatic heart } \\
\text { sound analysis } \\
\text { without } \\
\text { segmentation }\end{array}$ & 60 recording & $\begin{array}{l}\text { Envelope } \\
\text { Detection }\end{array}$ & $\begin{array}{c}\text { Geometric } \\
\text { mean }\end{array}$ & $\begin{array}{c}\text { Discrete } \\
\text { Wavelet } \\
\text { Transformation }\end{array}$ & $\begin{array}{c}\text { Not } \\
\text { Reported }\end{array}$ & $\begin{array}{c}\text { Not } \\
\text { Reported }\end{array}$ \\
\hline $\begin{array}{l}\text { Huiying L. } \\
\text { et. al. [13] }\end{array}$ & $\begin{array}{l}\text { A heart sound } \\
\text { segmentation } \\
\text { algorithm using } \\
\text { wavelet }\end{array}$ & Local Database & $\begin{array}{l}\text { Wavelet } \\
\text { Basis }\end{array}$ & $\begin{array}{l}\text { Additive } \\
\text { criterion } \\
\text { proposed } \\
\text { by } \\
\text { Coifman }\end{array}$ & $\begin{array}{c}\text { Discrete } \\
\text { Wavelet } \\
\text { Transformation }\end{array}$ & $72 \%$ & $\begin{array}{c}\text { Not } \\
\text { Reported }\end{array}$ \\
\hline
\end{tabular}




\begin{tabular}{|c|c|c|c|c|c|c|c|}
\hline $\begin{array}{l}\text { L. Zhong } \\
\text { et. al. [6] }\end{array}$ & $\begin{array}{c}\text { Application } \\
\text { Research on } \\
\text { Sparse Fast } \\
\text { Fourier } \\
\text { Transform } \\
\text { Algorithm in } \\
\text { White Gaussian } \\
\text { Noise }\end{array}$ & $\begin{array}{l}\text { Centre for } \\
\text { Biomedical } \\
\text { Engineering }\end{array}$ & SNR & $\begin{array}{l}\text { Number } \\
\text { of points } \\
\text { per } \\
\text { Bucket } \\
\text { (NPPB) }\end{array}$ & $\begin{array}{l}\text { Fast Fourier } \\
\text { Transformation }\end{array}$ & $90 \%$ & $\begin{array}{c}\text { Not } \\
\text { Reported }\end{array}$ \\
\hline $\begin{array}{l}\text { Proposed } \\
\text { work }\end{array}$ & $\begin{array}{c}\text { Machine } \\
\text { Learning Based } \\
\text { Improved } \\
\text { Automatic } \\
\text { Diagnosis of } \\
\text { Cardiac Disorder } \\
\text { and decreasing } \\
\text { the time } \\
\text { complexity by } \\
\text { automatic } \\
\text { database } \\
\text { updating strategy }\end{array}$ & $\begin{array}{c}\text { PhysioNet/CinC } \\
\text { challenge } 2016\end{array}$ & $\begin{array}{l}\text { MFCC, } \\
\text { Cepstrum } \\
\text { Analysis }\end{array}$ & $\begin{array}{c}\text { Statistical } \\
\text { mean and } \\
\text { median of } \\
\text { MFCC }\end{array}$ & $\begin{array}{l}\text { Support Vector } \\
\text { Method }\end{array}$ & $93.33 \%$ & $2.18 \mathrm{sec}$ \\
\hline
\end{tabular}

Table 3 shows the confusion matrix which demonstrates the accuracy of the proposed methodology by predicting the testing samples effectively. In this table 3 different set of training and testing are considered for evaluating the performance of the proposed work.

Table 4 shows the result of classification obtained by SVM classifier on multiplied testing sets. The table shows the performance of the classifier in terms of accuracy, sensitivity and specificity. This shows that the proposed algorithm can work efficient in identifying the abnormal heart sound.

Table 4: Classification Results
\begin{tabular}{|c|c|c|c|}
\hline $\begin{array}{c}\text { CLASSIFICATION } \\
\text { RESULT }\end{array}$ & $\begin{array}{c}\text { PERFORMANCE } \\
\text { RESULTS }\end{array}$ \\
\hline \multicolumn{4}{|c|}{ Case-I } \\
\hline True Positives & 20 & Accuracy & $95 \%$ \\
\hline False Negatives & 1 & Sensitivity & $95 \%$ \\
\hline True Negatives & 20 & Specificity & $90 \%$ \\
\hline False Positives & 0 & & \\
\hline \multicolumn{4}{|c|}{ Case-I } \\
\hline True Positives & 20 & Accuracy & $93.3 \%$ \\
\hline False Negatives & 1 & Sensitivity & $86.67 \%$ \\
\hline True Negatives & 20 & Specificity & $100 \%$ \\
\hline False Positives & 0 & & \\
\hline \multicolumn{4}{|c|}{ Case-III } \\
\hline True Positives & 9 & Accuracy & $95 \%$ \\
\hline False Negatives & 1 & Sensitivity & $90 \%$ \\
\hline True Negatives & 10 & Specificity & $100 \%$ \\
\hline False Positives & 0 & & \\
\hline
\end{tabular}

\section{DISCUSSION}

The existing method limits that the user has to improve the training data set periodically (over a period of time) by improvising the array of the input MFCCs Mean and Median, which increases the space complexity of the code as:

1. Increasing the lines of codes will increase the SLOC value of the program.
2. It increases the space complexity

3. Periodic updating of the code is much difficult for the person with zero programming knowledge.

The proposed method follows the iteration method using MFCCs mean and Median as perceptual features and SVM's Linear kernel classifier, in which the training data will improve itself by updating the set of values (if fall under the standard category, which is a normal frequency in this case) into the .csv (comma separated values) file, where the training data is being saved. The proposed method has following advantage:

1. Since the values are not stored in an array with in the program, it will decrease the SLOC value.

2. Further it will decrease the space complexity for the same cause.

No periodic updating required, so it will be much easier for the user to use it over a long period of time.

Table 5 represents a comparative chart of some existing methods with proposed method. The proposed method has obtained the high accuracy. This support that the proposed method can play an important contribution in determining the health status of the patient.

\section{CONCLUSION}

This paper presents an approach to diagnose the abnormality of the heart using machine learning discrimination of heart sounds. Since there is unavailability of cardiologists is rural areas, the proposed method will mark its presence by providing the Automatic diagnosis of Cardiac Disorders. The process consists of processing the PCG signal, applying a filter and using the discriminatory features in machine learning methodology which is further testing on the multiplied, non overlapping datasets. The computational complexity of the proposed method is low making the proposed method suitable for real time applications. As per the future projection regarding the proposed paper, the similar methodology can be used in various purpose in medical field.

\section{REFERENCES}

[1] Nadia Masood Khan, Muhammad Salman Khan, Gul Muhammad Khan, "Automated Heart Sound Classification from Unsegmented Phonocardiogram Signals Using Time Frequency Features", International Science Index, Computer 
and information Engineering Vol:12, no.8 ,2018 waset.org / Publication / 10009310,

[2] S. Hussain et al., "Classification of heart sound based on multipoint auscultation system," Systems, Signal Processing and their Applications (WoSSPA), 2013 8th International Workshop on, Algiers, 2013, pp.174-179.doi:

[3] 10.1109/WoSSPA.2013.6602357.

[4] Altman DG, Bland JM (1994). "Diagnostic tests. 1: Sensitivity and 2: specificity ". BMJ. 308 (6943): 1552. doi:10. 1136/bmj. 308.6943.1552.

[5] Machineti Vadicherla, Sheetal Sonawane, "Decision Support System For Heart Disease Based On Sequential Minimal Optimization in Support Vector Machine," International Journal of Engineering Sciences \& Emerging Technologies, Feb. 2013. ISSN: 2231 - 6604 Volume 4, Issue 2, pp: 19-26.

[6] D. Kumar, P. Carvalho, M. Antunes, R. P. Paiva, J. Henriques, "Heart murmur classification with feature selection," 2010 Annual International Conference of the IEEE Engineering in Medicine and Biology, Buenos Aires, 2010, pp. 4566-4569

[7] L. Zhong, L. Lichun, L. Huiqi, Application Research on Sparse Fast Fourier Transform Algorithm in White Gaussian Noise, Procedia Computer Science. Volume 107 pp 802-807.

[8] 2017F. Meziani, S.M. Debbal, A. Atbi, Analysis of phonocardiogram signals using wavelet transform. J Med Eng Technol. Volume 36 Issue 6, pp 283-302. 2012.

[9] Physionet. Physionet Challenge 2016.

[10] https://physionet.org/challenge/2016/. Accessed 11 May 2018

[11] G. Redlarski, D. Gradolewski, A. Palkowski, A System for Heart Sounds Classification. PLoS ONE, Volume 9, Issue 11, e112673. 2014.

[12] Altman, N. S. (1992). "An introduction to kernel and nearestneighbour nonparametric regression". The American Statistician. 46 (3):

175 185. doi:10.1080/00031305.1992.10475879

[13] Deng SW, Han JQ. Towards heart sound classification without segmentation via autocorrelation feature and diffusion maps. Future Generation Computer Systems 2016;60: 13-21.

[14] Yuenyong S, Nishihara A, Kongprawechnon W, Tungpimolrut K. A framework for automatic heart sound analysis without segmentation. In Biomedical Engineering Online, 2011; 10-13.

[15] Huiying L, Sakari L, Iiro H. A heart sound segmentation algorithm using wavelet. In 19th international Conference IEEE/EMBS, Chicago, IL, 1997

[16] Kao WC, Wei CC. Automatic phonocardiograph signal analysis for detecting heart valve disorders. Expert Systems with Applications 2011;38(6):6458-68. 